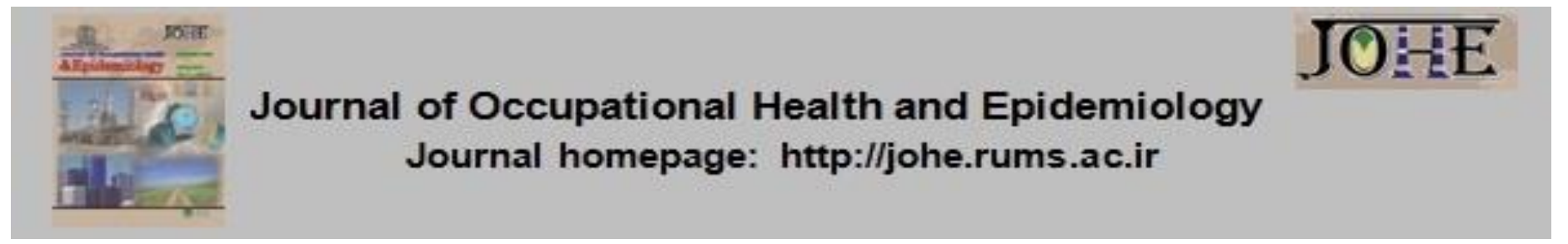

\title{
Prevalence of Musculoskeletal Disorders among Physicians at Mortaz Hospital in Yazd, Iran (2020)
}

Hamid Hoboubati ${ }^{1}$, Zakieh Saadatfar ${ }^{2}$, Masoud Khoshbin ${ }^{3}$, Gholamhossein Halvani ${ }^{4}$, Mohammadhossein Ahmadieh ${ }^{5}$, Rohollah Fallah Madvari ${ }^{4}$, Hamideh Bidel $6^{*}$

1. Assistant Prof., Dept. of Neurosurgery, School of Medicine, Shahid Sadoughi University of Medical Sciences, Yazd, Iran.

2. Graduated in Medicine, School of Medicine, Yazd University of Medical Sciences, Yazd, Iran.

3. Associate Prof., School of Medicine, Yazd University of Medical Sciences, Yazd, Iran.

4. Assistant Prof., Dept. of Occupational Health, School of Health, Shahid Sadoughi University of Medical Sciences, Yazd, Iran.

5. Assistant Prof., Dept. of Epidemiology, School of Health, Shahid Sadoughi University of Medical Sciences, Yazd, Iran.

6. MSc in Occupational Health and Safety, Dept. of Occupational Health and Safety, School of Public Health and Safety, Shahid Beheshti University of Medical Sciences, Tehran, Iran.

\section{Article Info}

* Corresponding author:

Hamideh Bidel,

E-mail:

hamidebidel@gmail.com

\section{Article history}

Received: Jun 2021

Accepted: Nov 2021

10.52547/johe.10.3.175

Print ISSN: 2251-8096 Online ISSN: 2252-0902

Peer review under responsibility of Journal of Occupational Health and Epidemiology
Citation: Hoboubati H, Saadatfar Z, Khoshbin M, Halvani G, Ahmadieh M, Fallah Madvari R, Bidel H. Prevalence of Musculoskeletal Disorders among Physicians at Mortaz Hospital in Yazd, Iran (2020). J Occu Health Epidemiol 2021; 10(3):175-82.

\begin{abstract}
Background: Due to their difficult working conditions, physicians are prone to injuries and musculoskeletal disorders affecting different parts of the body. This study aimed to investigate the prevalence of musculoskeletal disorders among physicians at Mortaz hospital in Yazd, Iran (2020)

Materials and Methods: The present study is a cross-sectional descriptive study conducted on 50 physicians at Mortaz Hospital in Yazd. The Nordic questionnaire and the Quick Exposure Check (QEC) method were employed to assess the prevalence of musculoskeletal disorders and analyze body postures at work. Chi-square and t-test were used to determine statistically significant relationships.

Results: Seventy percent of the subjects were male. The mean age of the samples was $47.3 \pm 8.4$ years. The point prevalence of musculoskeletal disorders in the lower back, neck, and knees were $52 \%, 30 \%$, and $24 \%$ respectively; and the periodic prevalence of these disorders were $56 \%, 38 \%$, and $34 \%$ in the back, neck, and shoulders respectively. According to the QEC results, $76 \%$ of the subjects needed further investigation and intervention in the future, and $20 \%$ were at an unacceptable risk level needing to be addressed immediately.

Conclusion: Physicians are exposed to many risk factors due to the working conditions that make them prone to various musculoskeletal disorders. Hence, to reduce the risk and prevalence of musculoskeletal disorders, interventional measures should be taken.
\end{abstract}

Keywords: Prevalence, Musculoskeletal Disorders, Physicians, Injury.

\section{Introduction}

According to the World Health Organization, musculoskeletal disorders refer to a group of diseases and disorders that affect the human musculoskeletal system, including muscles, nerves, tendons, ligaments, joints and cartilage. These disorders usually occur chronically [1, 2].
Feeling of pain and discomfort in different parts of the body is one of the main problems in the workplace [3], which has caused more than half of absences in the workplace and is the cause of more than one-third of job compensation requests among job groups [4]. Musculoskeletal discomfort and pain is the most common complaint of employees in the workplace, which reduces the 
efficiency and effectiveness of people and is also the main cause of disability of the workforce [5]. When work activities and conditions cause the development and exacerbation of musculoskeletal disorders, they are called work-related disorders. Accordingly, after respiratory diseases, musculoskeletal disorders are the second workrelated complication [6, 7]. Musculoskeletal disorders account for approximately $48 \%$ of all occupational diseases. In the United States, 65\% of all workplace illnesses are related to musculoskeletal disorders. Also in Iran, about 36\% of employees have poor physical conditions at work [8-10].

Musculoskeletal disorders cause working-hour losses, increased costs, and damage to the workforce. Health careers are among the occupations with the highest levels of musculoskeletal disorders [4]. Having different working conditions and patterns according to their medical specialties, physicians play a crucial role in the health care system in any society. These conditions lead to injuries and musculoskeletal disorders in different parts of the body. According to studies, the highest prevalence of musculoskeletal disorders among physicians is seen in the neck, back, and shoulders [11, 12]. Factors such as prolonged sitting or standing, frequent bending or rotation, multiple shifts, long working hours, high stress levels, and insufficient opportunity to rest between working hours, age, sex, height, and work experience affect the prevalence of musculoskeletal disorders among physicians [13, 14]. The Nordic Questionnaire, developed by Kornika et al. (1987), is one of the most comprehensive tools for assessing the prevalence of musculoskeletal disorders. This screening tool examines the presence or sensation of pain in nine areas of the body over a period of one week and one year. This questionnaire can be used to determine the prevalence of skeletal disorders in each area of the body $[15,16]$. There are several methods for assessing musculoskeletal disorders and postural analysis. Quick Exposure Check (QEC) is a widely used risk assessment tool to assess exposure to risks for musculoskeletal disorders. This method makes it possible to assess a person with a range of risk factors for musculoskeletal disorders [14]. Due to the type of working conditions of physicians and their exposure to risk factors for musculoskeletal disorders, ergonomic evaluation must be conducted. This study aimed to investigate the prevalence of musculoskeletal disorders among physicians at Mortaz hospital in Yazd.

\section{Materials and Methods}

The present study is a cross-sectional descriptive study conducted on physicians working at Mortaz Hospital in Yazd in 2020. The total number of physicians working at Mortaz Hospital in Yazd was 168. The inclusion criteria were as follows: agreeing to participate in the study, having at least one year of medical experience. Incomplete response to the questionnaire as well as unwillingness to continue cooperation were the exclusion criteria. Based on inclusion/excluding criteria, finally, fifty physicians were selected. The sample size was based on similar studies $[13,17$, 18]. The Nordic questionnaire was used to assess the prevalence of musculoskeletal disorders in various organs of the body as well as demographic information of individuals, and the QEC method was used to analyze body postures at work.

This study was approved by the Ethics committee of Vice Chancellor for Research at Yazd Azad University (Code: IR.IAU.YAZD.REC.1399.016).

Nordic Questionnaire: The Nordic General Questionnaire, designed by Korinka et al. in 1987 [16], is widely used to assess the prevalence of musculoskeletal disorders in various parts of the body. The Nordic General Questionnaire assessed only three areas of the body, i.e. the back, shoulders, and neck. Therefore, in 2009, the Nordic Extended Questionnaire was developed by Dawson [19]. The Nordic Extended Questionnaire is a simple and complete tool that provides a wealth of information on musculoskeletal disorders in nine areas of the body [15]. In general, this questionnaire consists of two parts: the first part includes questions about the demographic information of the person, including age, gender, working hours; the second part contains questions about having pain in nine areas of the body (neck, shoulders, elbows, hands/wrists, upper back, lower back, knees, buttocks and legs/ankles). The history of pain in these areas is examined in two time periods of the last 7 days and the last 12 months, which indicate the point and periodic prevalence of musculoskeletal disorders in the individual, respectively. In addition, it asks if these problems have caused the person to quit or be unable to work [20-22]. The Nordic questionnaire does not have an overall score. Instead, it determines the frequency of damage in each area of the body. The questionnaire is structured in such a way that it can be completed in two ways: through interviews with workers or by individuals themselves [23]. In this study, the questionnaire was completed by physicians in the workplace. Initially, the presence or absence of pain in nine 
areas of the body is determined by the answer yes or no. If the answer to pain in that area of the body is positive, the respondent must answer 11 questions about the presence or absence of pain during life, the prevalence and consequences of pain. If the answer to the question of pain in one area of the body is negative, the rest of the questions related to that area will be automatically negative [19]. The results of the validity and reliability of the Persian version of this questionnaire reported its internal consistency of 0.8 and Repeatability with kappa coefficient $>0.7$ and $P<0.001$ [2, 24]. The validity and reliability tests of the original version of the Nordic questionnaire varied from $0-20 \%$ and $0-23 \%$, respectively [16].

QEC is a widely used method to assess the risk of musculoskeletal disorders and postural analysis developed by Lee and Buckle (1998) [25]. In this method, the posture is evaluated based on the individual's observations. In posture evaluation methods, the most frequent or worst posture is selected as the final posture and for evaluation. The QEC method assesses the exposure of four areas of the body, including the back, shoulders/arms, wrists/hands, and neck, that are more at risk for skeletal disorders than other areas of the body [25, 26]. This method allows the worker to assess the risk factors for musculoskeletal disorders, including posture, repetition, force applied, and duration of exposure. The combined effect and interaction of these factors are done using the scoring table of the QEC method [27]. In this method, according to the questioner's observation and the worker's answer, information about the maximum displaced weight, duration of work, the maximum force applied, exposure to vibration, visual needs of work, as well as the level of exposure to stress during work are recorded [27]. The QEC method checklist consists of two parts: a form filled by the observer to assess the level of exposure of the four areas of the body to the risk factors for injuries of musculoskeletal disorders, and a form of evaluation and judgment of the worker about his work. Finally, exposure assessment scores are obtained by combining the scores of the observer and the evaluated person's responses. In the part completed by the evaluator, the letter $A$ to $G$ is used to determine the different positions of the body during work evaluating $A$ (waist posture), B (lumbar movement in manual carrying tasks), C (shoulder/arm posture), D (shoulder/arm movement), E (wrist/hand posture), $\mathrm{F}$ (wrist/hand movement), and $\mathrm{G}$ (neck posture). In the checklist completed by the evaluated person, the questions are classified using the letters a to $\mathrm{g}$ : a (Load handling weight), b (Load handling time), c (Maximum force applied), d (Vibration), e (Visual requirements of the work), $f$ (Speed of work), and $g$ (Stress). Finally, the calculation of points for each person is done using scoring tables. The following is a description of how to calculate the final score of each section. For example, for the shoulder/arms section, the code related to the height of the hands (shoulder posture) and weight, hand height and period (time) of work, period and weight of the load, coefficient Repetition and load weight, coefficient of repetition and work cycle are each merged into a separate matrix and a score is calculated for that matrix. Next, to calculate the exposure score independently for each part of the body, the score obtained for that part is divided by the maximum score for that area of the body. The maximum score for the waist, shoulder, and hand/wrist area is 56 and for the neck area is 18 . To calculate the exposure score for the whole body, the score for each of the four areas is added together and then the resulting number is divided by the maximum possible score for the whole body. The maximum score for the whole body is 176 for manual material handling and 162 for other tasks. The final score is obtained as a percentage of exposure [25, 28]. Table 1 shows the exposure score of the QEC classification.

Table 1. Levels for Quick Exposure Check scors [29, 30]

\begin{tabular}{ccccc}
\hline \multirow{2}{*}{ Area } & \multicolumn{3}{c}{ Exposure level } \\
\cline { 2 - 5 } & Low & Medium & High & Very high \\
\hline Waist & $10-20$ & $22-30$ & $32-40$ & $42-56$ \\
\hline Shoulder & $10-20$ & $22-30$ & $32-40$ & $42-56$ \\
\hline Wrist/hand & $10-20$ & $22-30$ & $32-40$ & $42-56$ \\
\hline Neck & $4-6$ & $8-10$ & $12-14$ & $16-18$ \\
\hline
\end{tabular}

Finally, according to the scores earned, the level of corrective actions is divided into four categories, which are listed in table 2 . It should be noted that the third and fourth correctional levels require immediate corrective action [1]. 
Table 2. QEC scoring and corrective actions [29, 30]

\begin{tabular}{cl}
\hline Total QEC score & \multicolumn{1}{c}{ Exposure assessment and corrective actions } \\
\hline Score less than $40 \%$ & Indicates acceptable musculoskeletal load \\
\hline Score between $41-50 \%$ & Further investigation is needed and changes may be needed. \\
\hline Score between $51-70 \%$ & Further checks and changes should be made as soon as possible. \\
\hline Score more than $70 \%$ & Need to review and make changes immediately \\
\hline
\end{tabular}

Data analysis was performed using SPSS software (ver.21). Chi-square and t-test were used to determine the statistically significant relationship. $P$.value $\leq 0.05$ was significant.

\section{Results}

35 subjects $(70 \%)$ were male and the remaining 15 (30\%) were female. The mean age of the samples was $47.3 \pm 8.4$ years ranging from 33 to 70 years. The work experience of the subjects was between 4 to 41 years, so the average work experience of the subjects was $18.3 \pm 8.4$ years. The height of the subjects was between 150 to $189 \mathrm{~cm}$ with an average of $172.46 \pm 9.2 \mathrm{~cm}$ and their weight was between 52 to $116 \mathrm{~kg}$ with an average of $81.54 \pm 15.8 \mathrm{~kg}$. The height and weight of the participants were measured using a tape measure and a digital scale, respectively. Body mass index was calculated using both weight and height $(\mathrm{kg} / \mathrm{m} 2)$. Based on the classification of body mass index by health associations, $2 \%$ of the subjects were in the underweight group, 34\% in the normal group, $40 \%$ in the overweight group, and $24 \%$ in the obese group. The highest frequency of body mass index belonged to overweight body mass. In terms of marriage, 47 the subjects (94\%) were married and $3(6 \%)$ were single. Eleven (22\%) cases of the subjects were just sitting at work, 36 (72\%) were both sitting and standing during work hours, and the rest $(6 \%)$ were standing. Twentyone $(42 \%)$ subjects did not have another job. The daily working hours of 10 people (20\%) were 8 hours and less and the daily working hours of 40 people (80\%) were 10 hours and more. Half of the subjects had more than 17 years of work experience and the other half had less than 17 years of work experience.

The results showed that $72 \%$ (36) of the subjects complained of pain in at least one of the 9 areas studied during the last 7 days, and $80 \%$ (40) had such complaints in the past year. $28 \%$ (14) of the subjects did not have any symptoms of the disorder (discomfort) in the 9 organs examined during the last 7 days, and 20\% (10) did not have such symptoms in the past year. Moreover, due to pain or discomfort in one of the nine areas surveyed, $28 \%$ (14 people) had been forced to rest, reduce work activity, leave work or inability to perform activities at work or at home in the last 12 months. The relative frequency and percentage of people with the disorder (discomfort) in the 9 areas studied are shown in Table 3.

Table 3. Relative frequency of musculoskeletal disorders in nine organs

\begin{tabular}{ccc}
\hline Area & $\begin{array}{c}\text { Last 7 days } \\
\mathbf{n}(\%)\end{array}$ & $\begin{array}{c}\text { One year ago } \\
\mathbf{n}(\%)\end{array}$ \\
\hline Neck & $15(30)$ & $19(38)$ \\
\hline Shoulder & $9(18)$ & $17(34)$ \\
\hline Elbow & $3(6)$ & $4(8)$ \\
\hline Wrist / hand & $5(10)$ & $9(18)$ \\
\hline Back & $11(22)$ & $12(24)$ \\
\hline Waist & $26(52)$ & $28(56)$ \\
\hline Hip & $11(22)$ & $13(26)$ \\
\hline Knee & $12(24)$ & $16(32)$ \\
\hline
\end{tabular}

Table 4 shows the relative prevalence of musculoskeletal disorders due to demographic variables in the study population. According to the table below and regarding $p$-values in men and women, there was no significant relationship between the presence of pain in 9 organs in the past year and gender. Based on the findings of the study, the age groups were divided into 33-50 and 51-70 years. The results show that there was no significant relationship between the prevalence of musculoskeletal disorders and age. To evaluate the effect of body mass index on the prevalence of musculoskeletal disorders in individuals, BMI value was classified into three groups of less than 25, 25 and, more than 25 . The results of the Chi-square test show that there was no significant relationship between body mass index and musculoskeletal disorders in nine areas of the body. There was also no significant relationship between work experience and the prevalence of musculoskeletal 
disorders. To investigate the effect of the type of activity on the prevalence of musculoskeletal disorders, individuals were divided into two groups of sitting and sitting-standing work activity. The results of the statistical test did not show a significant relationship between the type of work activity and the prevalence of musculoskeletal disorders. Based on the p-value, there was no significant relationship between the presence of pain or discomfort in the other 9 areas and the duration of daily activity.

Table 4. Relationship between the frequency of musculoskeletal disorders in the nine organs of the body and demographic variables

\begin{tabular}{|c|c|c|c|c|c|c|}
\hline \multirow[b]{2}{*}{$\begin{array}{c}\text { The location of pain } \\
\text { or discomfort }\end{array}$} & \multicolumn{6}{|c|}{ P-value } \\
\hline & $\underset{\bullet}{\operatorname{Sex}}$ & Age & $\begin{array}{c}\text { BMI } \\
\mathbf{\square}\end{array}$ & $\begin{array}{c}\text { Work } \\
\text { experience } \\
\end{array}$ & $\begin{array}{c}\text { Type of work } \\
\text { activity }\end{array}$ & $\begin{array}{c}\text { Work } \\
\text { duration }\end{array}$ \\
\hline Neck & 0.409 & 0.121 & 0.190 & 0.216 & 0.754 & 0.414 \\
\hline Shoulder & 0.312 & 0.814 & 0.304 & 0.902 & 0.706 & 0.962 \\
\hline Elbow & 0.574 & 0.100 & 0.127 & 0.611 & 0.100 & 0.569 \\
\hline Wrist / hand & 0.415 & 0.684 & 0.234 & 0.110 & 0.726 & 0.664 \\
\hline Back & 0.248 & 0.631 & 0.825 & 0.243 & 0.880 & 0.232 \\
\hline Waist & 0.320 & 0.696 & 0.217 & 0.412 & 0.425 & 0.716 \\
\hline Hip & 0.527 & 0.640 & 0.830 & 0.624 & 0.200 & 0.184 \\
\hline Knee & 0.146 & 0.213 & 0.631 & 0.159 & 0.422 & 0.113 \\
\hline Ankle & 0.629 & 0.643 & 0.642 & 0.101 & 0.105 & 0.569 \\
\hline
\end{tabular}

*Significance level of $p$-value $<0.05 \bullet$ Chi-square test, $\quad$-T-test

The frequency of exposure levels in four areas of the body based on the score calculated in the study population is shown in table 5 . In addition, the level of vibration exposure in the study population was very low. $90 \%$ (45) of people had low levels of vibration exposure.

Table 1. Frequency of exposure to risk factors for musculoskeletal disorders in the four areas calculated based on points

\begin{tabular}{ccccc}
\hline \multirow{2}{*}{ Area } & \multicolumn{4}{c}{ Exposure level; $\mathbf{n}(\%)$} \\
\cline { 2 - 5 } & Low & Medium & High & Very high \\
\hline Waist & 0 & 0 & $6(12)$ & $43(86)$ \\
\hline Shoulder & 0 & $35(70)$ & $13(26)$ & $1(2)$ \\
\hline Wrist / hand & 0 & $36(72)$ & $10(20)$ & $3(6)$ \\
\hline Neck & 0 & $1(2)$ & $29(58)$ & $19(38)$ \\
\hline
\end{tabular}

The results of classification frequency and percentage of studied postures showed that: 1 $(2 \%)$ subject was at the intermediate level, 38 $(76 \%)$ persons were at the high level, and 10 $(20 \%)$ persons were at a very high level. Therefore, to improve working conditions, taking corrective measures is necessary. Examination of the results of the relationship between demographic variables and QEC score showed that there was no significant relationship between age, sex, work experience, and body mass index and the level of exposure to risk factors for musculoskeletal disorders.

\section{Discussion}

This study aimed to investigate the prevalence of musculoskeletal disorders among physicians at Mortaz hospital in Yazd. According to the results of the Nordic questionnaire, during the last 7 days, lower back, neck and knee had the highest prevalence of musculoskeletal disorders in the study population. Moreover, during the past year, lower back, neck and shoulders had the highest prevalence of musculoskeletal disorders. In the study of Zolfaghari et al., the neck and back had the highest prevalence of musculoskeletal disorders during the past year. According to the results of this study, $60.4 \%$ and $31.7 \%$ of people complained of pain and discomfort in the neck and back, respectively [14]. The study of Vakili et al. showed that during the past week, the lumbar region $(30.20 \%)$, knee $(25.40 \%)$ and hand $(23.70 \%)$ had the highest prevalence of musculoskeletal disorders [20]. The study of Jafari et al. showed that the highest feeling of pain and discomfort had been reported in the lumbar region with a prevalence of $51.78 \%$. Neck and back with 33.92 and 21.42 percent were in the second and third ranks, respectively, with the highest prevalence of musculoskeletal disorders [30]. Rahmani et al.'s study showed that the neck, back and shoulders were the most common levels of musculoskeletal discomfort with a prevalence of $73 \%, 62 \%$, and $41 \%$, respectively [1]. The results of studies on the prevalence of musculoskeletal 
disorders in different parts of the body were consistent with the results of the present study and showed that the neck, back and shoulders were among the most vulnerable organs.

Examining the relationship between demographic variables and the prevalence of musculoskeletal disorders in the nine organs examined in the Nordic questionnaire showed that there was no significant relationship between gender and the prevalence of disorders. There was also no significant relationship between work experience, age, and BMI and the prevalence of musculoskeletal disorders. In the study of Rahimi et al. (2020), a significant relationship was observed between age and work experience and the prevalence of musculoskeletal disorders. As each unit of work experience (year) increased, musculoskeletal pain increased 1.2 times [1]. The results of previous studies also show that age is one of the influential variables in the prevalence of musculoskeletal disorders. As one of the uncontrollable and non-manipulative risk factors, age indicates the risk of musculoskeletal disorders, which is not consistent with the results of the present study. Musculoskeletal disorders are significantly higher in younger people with less work experience. Explaining this difference, it can be said that younger people with less work experience may have less knowledge about body mechanics while working [13, 14]. While other studies show that increases in age and work experience are significantly associated with the prevalence of musculoskeletal disorders [28, 31, 32].

According to the QEC results, the risk level of musculoskeletal disorders in the four areas showed that in the lumbar region, $12 \%$ of subjects were at high risk and $86 \%$ of subjects were at very high risk. In the shoulder area, $26 \%$ of subjects had a high level of risk and only $2 \%$ had a very high level of risk. $20 \%$ of subjects had a high risk of musculoskeletal disorders in the wrist/hand area. In the neck area, $58 \%$ and $38 \%$ of people were at high and very high risk levels, respectively. Based on the QEC results, the condition of subjects at risk for musculoskeletal disorders was such that $76 \%$ of people needed further investigation and intervention in the future. In addition, $20 \%$ of people were at an unacceptable level of risk that should be immediately intervened and corrected. The study of Jafari et al. showed that $12.5 \%$ of people were at moderate risk level, $46.42 \%$ and $35.71 \%$ were at high risk level and very high musculoskeletal disorders, respectively. In general, $82.13 \%$ of the subjects in this study were at high and very high risk of musculoskeletal disorders, which was consistent with the results of the present study [30]. In the study of Yeganeh et al., the total QEC score among the subjects was $99.40 \%$, indicating the high risk level of musculoskeletal disorders [27]. In a study conducted on nurses in which the risk level of musculoskeletal disorders was measured using the QEC method, the results showed high and very high risk levels in the neck, shoulder, hand/wrist, and waist [14], which was consistent with the results of the present study. Prolonged sitting and standing, excessive bending or rotation, multiple work shifts were the main reasons for the high prevalence of musculoskeletal disorders in health workers [14]. According to the results of the present study, physicians are among the occupations at high risk of musculoskeletal disorders.

One of the limitations of the study was the small sample size. It is recommended that future studies be conducted with a larger sample size and with an interventional perspective to reduce the risk of musculoskeletal disorders among physicians.

\section{Conclusion}

The results of the present study showed the high level of prevalence of musculoskeletal disorders among physicians. Physicians are exposed to many risk factors due to their working conditions, which makes them prone to many musculoskeletal disorders. Moreover, the risk level of musculoskeletal disorders in the study population was very high. To reduce the risk and prevalence of musculoskeletal disorders, the researchers recommend taking intervention measures and performing before- after examination. In addition, the necessary training on how to carry the load, determine work-rest cycles, review the arrangement of work shifts, manage working hours, and deal with stress is recommended.

\section{Acknowledgement}

The researchers would like to express their gratitude and appreciation to the respected physicians at Mortaz Hospital in Yazd for their kind collaboration.

Conflict of interest: None declared.

\section{References}

1. Rahmani R, Shahnavazi S, Fazli B, Ghasemi F. Ergonomic Risk Assessment of Musculoskeletal Disorders in a Cement Factory Workers Using QEC Technique. Pajouhan Sci J 2020; 18(2):64-72. 
2. Rahmati-Yami M, Azarmi E, Rahnama L, Hosseinzadeh S, Karimi N. The Relationship between Work-Related Musculoskeletal Disorders and Types of Used Treatment Methods among Iranian Physiotherapists. Arch Rehabil 2020; 21(1):22-39.

3. Dekker $\mathrm{S}$. The criminalization of human error in aviation and healthcare: A review. Saf Sci 2011; 49(2):121-7.

4. Akhlaghi Pirposhteh E, Golrokh F, Ebrahimi HR, Salehi Sahl Abadi A. The prevalence of musculoskeletal disorders among administrative and service staff of selected hospitals of Shahid Beheshti University of Medical Sciences and their associated risk factors. Health Dev J 2020; $9(2): 124-36$

5. Bernal D, Campos-Serna J, Tobias A, VargasPrada S, Benavides FG, Serra C. Work-related psychosocial risk factors and musculoskeletal disorders in hospital nurses and nursing aides: a systematic review and meta-analysis. Int $\mathrm{J}$ Nurs Stud 2015; 52(2):635-48.

6. Shokati B, Yektakooshali MH, Zareiyan A, Akbari Negad S, Soroush A. The Prevalence of Work-Related Musculoskeletal Disorders among X-Ray Radiographers Those Working in Radiology Centers of the Hospitals Affiliated in AJA University of Medical Sciences: A Cross Sectional Study. Milit Care Sci 2018; 4(3):198206.

7. Bernard BP, Putz-Anderson V. Musculoskeletal Disorders and Workplace Factors: A Critical Review of Epidemiologic Evidence for WorkRelated Musculoskeletal Disorders of the Neck, Upper Extremity, and Low Back. United States: Department of Health and Human Services, Public Health Service, Centers for Disease Control and Prevention, National Istitute for Occupational Safety and health; 1997 Jul. 590 p. Report No.:97B141.

8. Helander M. A guide to ergonomics of manufacturing. London, United Kingdom: Taylor \& Francis: 1995.

9. Skandari D, Noorizadeh $N$, Seadati $H$, Mohammadpour S, Gholami A. The prevalence of musculoskeletal disorders and occupational risk factors in Kashan SAIPA automobile industry workers by key indicator method (KIM), 1390. Health Saf Work 2012; 2(1):27-36.

10. Nikravan Golsefidi F, Ebrahimi Atri A, Hashemi Javaheri AA. A Comparison of Musculoskeletal Disorders of Neck and Shoulder Girdle in Male Computer Users with and Without Physical Activity. J Exerc Sci Med 2015; 7(2):205-20.

11. Aminian $O$, Pouryaghoub G, Shanbeh M. One year study of musculoskeletal disorders and their relation to occupational stress among office workers: a brief report. Tehran Univ Med 2012; 70(3):194-9.

12. Askaripoor T, Kermani A, Jandaghi J, Farivar F. Survey of Musculoskeletal Disorders and Ergonomic Risk Factors among Dentists and
Providing Control Measures in Semnan. J Health 2013; 4(3):241-8.

13. Zareei S, Norouzi E, Nekoei Esfahani A, Kanani B. Prevalence of Work-Related Musculoskeletal Disorders amongst Obstetrics and Gynaecology Professionals. Med J Mashhad Univ Med Sci 2020; 62(6):1866-73.

14. Zolfaghari F, Zare R. Ergonomic Posture Evaluation and Risk Factors for Musculoskeletal Disorders among Nurses in Arak City by QES Method. Rehab Res Nurs 2020; 6(3):17-24.

15. Mokhtarinia $H$, Shafiee $A$, Pashmdarfard $M$. Translation and localization of the Extended Nordic Musculoskeletal Questionnaire and the evaluation of the face validity and test-retest reliability of its Persian version. J Ergon 2015; 3(3):21-9.

16. Kuorinka I, Jonsson B, Kilbom A, Vinterberg $H$, Biering-Sørensen $F$, Andersson $G$, et al. Standardised Nordic questionnaires for the analysis of musculoskeletal symptoms. Appl Ergon 1987; 18(3):233-7.

17. Ahmadi Motemayel F, Abdolsamadi $H$, Roshanaei G, Jalilian S. Prevalence of Musculoskeletal Disorders among Hamadan General Dental Practitioners. Avicenna J Clin Med 2012; 19(3):61-6.

18. Yazdanian M, Moradi K, Sobhani V, Akbari H, Kazemipour M, Shamsoddini A, et al. Assessing the Prevalence of Musculoskeletal Disorders and Posture Conditions during Work Time of Dentists in a Dentistry Clinic affiliated to a Military College in Tehran in 2017. J Mil Med 2018; 20(2):222-30.

19. Dawson AP, Steele EJ, Hodges PW, Stewart S. Development and test-retest reliability of an extended version of the Nordic Musculoskeletal Questionnaire (NMQ-E): a screening instrument for musculoskeletal pain. J Pain 2009; 10(5):517-26.

20. Vakili-Basir A, Gholami-Fesharaki M. The Study of the point and period prevalence of musculoskeletal disorders in the steel industry workers. Daneshvar Med 2020; 26(6):33-40.

21. Gómez-Rodríguez R, Díaz-Pulido B, GutiérrezOrtega C, Sánchez-Sánchez B, TorresLacomba M. Cultural Adaptation and Psychometric Validation of the Standardised Nordic Questionnaire Spanish Version in musicians. Int $\mathrm{J}$ Environ Res Public health 2020; 17(2):653.

22. Rafeemanesh E, Ketabi Yazdi D, Ahmadifar M, Bidel $H$, Abbasi Balochkhaneh F. Study of Musculoskeletal Disorders Prevalence and Ergonomic Conditions by ROSA in Administrative Staff of Mashhad University of Medical Sciences. Int J Bus Manag 2019; $4(2): 82-9$.

23. Crawford JO. The Nordic Musculoskeletal Questionnaire. Occup Med 2007; 57(4):300-1.

24. Namnik N. Reliability and validity of the Persianversion of the Nordic Questionnaire in industrial 
workers with musculoskeletal disorders. [MSc thesis]. Ahvaz: Jundishapur University of Medical Science; 2013.

25. David G, Woods V, Li G, Buckle P. The development of the Quick Exposure Check (QEC) for assessing exposure to risk factors for work-related musculoskeletal disorders. Appl Ergon 2008; 39(1):57-69.

26. Choobineh A, Tabatabaee SH, Behzadi M. Musculoskeletal problems among workers of an Iranian sugar-producing factory. Int J Occup Saf Ergon 2009; 15(4):419-24.

27. Yeganeh R, Yarahmadi R, Damiri Z. Survey of Role of Didactic Interventional ErgonomicSafety Program on Workers' Productivity (CaseSeries Study of Electrical Assembling Industry). Health saf Work 2020; 10(3):201-11

28. Polanyi MF, Cole DC, Beaton DE, Chung J, Wells $R$, Abdolell $M$, et al. Upper limb work-related musculoskeletal disorders among newspaper employees: cross-sectional survey results. Am J Ind Med 1997; 32(6):620-8.
29. Li G, Buckle P. A Practical Method for the Assessment of Work-Related Musculoskeletal Risks-Quick Exposure Check (QEC). Proc Hum Factors Ergon Soc Annu Meet 1998; 42(19):1351-5.

30. Jafari B, Yousef Pour AR, Naji M. The Effect of a Corrective Exercise Course on the Musculoskeletal Disorders of a Military Unit Soldiers. J Mil Med 2020; 22(3):235-43.

31. Maroufi F, Salavati A, Marabi J, Foruzanfar F. Evaluation the Effectiveness of Ergonomic Educational Interventions by Training the Basics of Ergonomics and Exercise on Neck Pain in Nurse Staff of Tohid Hospital of Sanandaj. Payavard Salamat 2017; 11(4):433-40.

32. Juibari L, Sanagu A, Farrokhi N. The relationship between knowledge of ergonomic science and the occupational health among nursing staff affiliated to Golestan University of Medical Sciences. Iran J Nurs Midwifery Res 2010; 15(4):185-9. 